\title{
Alzheimer's disease and its treatment costs: case study in the Czech Republic
}

\author{
This article was published in the following Dove Press journal: \\ Neuropsychiatric Disease and Treatment \\ II September 2015 \\ Number of times this article has been viewed
}

\author{
Hana Mohelska' \\ Petra Maresova ${ }^{2}$ \\ Martin Valis ${ }^{3}$ \\ Kamil Kuca ${ }^{4,5}$ \\ 'Department of Management, \\ 2Department of Economy, Faculty \\ of Informatics and Management, \\ University of Hradec Králové, \\ ${ }^{3}$ Department of Neurology, Charles \\ University in Prague, Faculty of \\ Medicine in Hradec Králové and \\ University Hospital Hradec Králové, \\ ${ }^{4}$ Biomedical Research Centrum, \\ University Hospital Hradec Králové, \\ ${ }^{5}$ Center for Basic and Applied \\ Research, Faculty of Informatics and \\ Management, University of Hradec \\ Králové, Hradec Králové, Czech \\ Republic
}

\begin{abstract}
This paper deals with the analysis of the costs, applied, for example, when treating specific diseases - an important aid in prioritizing the process of resource allocation. In our review, the specific disease is dementia caused by Alzheimer's disease. This paper aims to provide more information on the partial costs per patient that are calculated according to the aggregated data from publicly available sources as well as from the results of authors' own investigation. The University Hospital in Hradec Králové and the General Health Insurance Company of the Czech Republic participated in this research. The elementary research objective was to compare the costs per patient diagnosed early onset, to those of the patient diagnosed later. The Czech Republic lacks information regarding dementia. Therefore, these issues require attention. The methods used in this paper included time series analyses, methods of direct questioning, interviews with experts, and analyses of medical documentation. These methods were combined to exploit their particular advantages and to ensure the issues discussed, were covered. The investigation showed that the underpinning of patients with Alzheimer's disease at early onset is advantageous from an economic perspective, because the cost of outpatient care is much lower compared with that of inpatient care. The international comparisons of the volume of care provided should be approached with great caution. These are based solely on the facts of various expert estimates and are not usually supported by hard data. Yet, they still illustrate the overall view of our ability to take care of people with dementia. According to experts, care in the Czech Republic significantly lags behind the rest of developed Europe. While services are provided to $26 \%$ of people with dementia in Germany and 50\% in France, the experts estimate that services are provided to only $10 \%$ of the population in the Czech Republic. If we were to offer a similar volume of services in the Czech Republic, to the same extent as the average in Europe, we would have to triple the existing capacities.
\end{abstract}

Keywords: mental health expenditure, Czech Republic, dementia, costs, Alzheimer's disease

\section{Introduction}

The risk of developing dementia increases with age. While the disease occurs occasionally in younger age groups, it predominates at retirement age. The incidence of the disease increases with each passing year. In the Czech Republic, its prevalence is highest in the oldest age groups, (over 80 years) in excess of ten occurrences. Every 25 th person suffering from dementia has not yet reached 60 years of age, whereas every eighth person is older than 80 years. ${ }^{1}$ In the group of people up to 65 years, every 866th person suffers from dementia. On the contrary, every 13 th person in the age group over 65 years suffers from it. In the case of the oldest age category, over 80 years of age, every fifth person suffers from dementia. In the age group over 90 years, every second person suffers from it. ${ }^{1}$ The number of people suffering from dementia in Prague is almost 19,000, which is logical as the capital city has the oldest 
population structure. ${ }^{1}$ There are nearly 17,000 people with dementia in the South Moravian Region, whereas there are 16,000 and 15,800 people in the Central Bohemian Region and Moravian-Silesian Region, respectively. The lowest number of people with dementia $(3,600)$ live in the Karlovy Vary Region, which is also the region with the youngest population structure.

It has always been difficult to determine the number of people suffering from Alzheimer's disease or other types of dementia in the Czech Republic. To learn more about who takes care of the needy, and what services are provided to them, is even more complicated. With the exception of the selected data from the Institute of Health Information and Statistics (IHIS CR), ${ }^{2}$ Research Institute for Labor and Social Affairs, ${ }^{3}$ and interim reports of the relevant ministries, there are almost no relevant resources that could be used, although service providers are required to publish huge amounts of data. In the health statistics IHIS CR, where the data is most available, the selected indicators are published complexly in a 4-year period. This interval is definitely not sufficient and therefore the data usability is limited. Moreover, learning more about the oldest age groups (over 80 years) is also impossible because only aggregated data are presented. ${ }^{4}$ Nevertheless, the importance of this age category will grow and that might be a motivation for more appropriate and more often data provision.

Even though there were attempts to unify the care for people with dementia, it still takes place in separated and unconnected sectors. Part of the care is provided through the health care system and some through social services. Despite repeated efforts, the specific interface of these systems in the form of long-term social and health care is still unanchored. A substantial part of the services is also provided on an informal basis by family members and other carers at home. We know almost nothing about this area. Among these, commercial interest in the context of the gray economy is followed in a smaller number of cases.

\section{Methods}

The methods used in this paper included time series analyses, methods of direct questioning, interviews with experts, and analyses of medical documentation. The data used were nonpublic, which were provided by the scientific cooperation of the Faculty of Informatics and Management, University of Hradec Králové, and the Hradec Králové branch of the General Health Insurance Company of the Czech Republic. Data were monitored in time series from 2010 to 2014 for the entire Czech Republic. The General Health Insurance Company of the Czech Republic is the largest insurance company in the Czech Republic. Approximately $58.3 \%$ of all the insured people in the Czech Republic are clients of

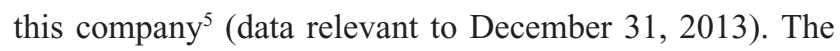
paper also used data from large university hospitals, which are managed by the Czech Republic Ministry of Health, because these hospitals deal with the issue of Alzheimer's disease. Moreover, the cost can be distinguished into outpatient and inpatient costs. Furthermore, the paper is based on the data present in the comprehensive report of the Care for Patients Treated for Dementia in Out-patient and In-patient Facilities of the Czech Republic in 2008-2012, published by the Institute of Health Information and Statistics of the Czech Republic (IHIS CR) in Prague on December 31, 2013. ${ }^{2}$ The authors also obtained data from their own investigation in the form of a guided interview with an expert, in this case with the Head of the Department of Neurology, which took place in the University Hospital in Hradec Králové from September to December 2014.

The results are related to diagnoses according to the International Classification of Diseases (ICD), ie, G30 Alzheimer's disease, G30.0 Alzheimer's disease with early onset, G30.1 Alzheimer's disease with late onset, G30.8 Other Alzheimer's disease, and G30.9 Alzheimer's disease unspecified. ${ }^{5}$ Except from the later, the diagnosis of F00 is dementia in Alzheimer's disease, and diagnoses of F01-F03 are other dementias.

\section{Results and discussion}

As mentioned earlier, Alzheimer's disease is of extreme importance. The care for patients might be divided into outpatient and inpatient care. These two approaches involve totally different practices and consequently different costs and demands of other resources.

\section{Outpatient care and its costs}

In 2012, 15,352 patients with the diagnosis of F00 (dementia in Alzheimer's disease) and 21,279 patients with the diagnoses of F01-F03 (other dementias) were treated in outpatients facilities in the Czech Republic. ${ }^{2}$

Based on the investigation of the research team in the University Hospital in Hradec Králové, data were obtained through a guided interview with the Head of the Department of Neurology. Moreover, the outcomes were supported by the real data obtained from the Department of Neurology. ${ }^{6}$ Hort et al ${ }^{7}$ provided recommendations for clinical diagnoses; blood tests; neuropsychology, neuroimaging, electroencephalography, and cerebrospinal fluid (CSF) analysis; genetic testing; disclosure of diagnosis; treatment of Alzheimer's disease; behavioral and psychological symptoms in dementia; legal issues; and counseling and support for caregivers. This research team revised 
all the available data and compared them with the European Federation of Neurological Societies (EFNS) guideline. Further data are illustrated in Table 1, which exemplify good practice from the Department of Neurology in the University Hospital in Hradec Králové, Czech Republic. Points represent the assessment of particular medical examination or treatment according to the Act No 324/2014 Coll. ${ }^{8}$

Test for tau protein may be used as a supplemental test to help with the establishment of a diagnosis of Alzheimer's disease. Moreover, its results can distinguish between Alzheimer's disease and other forms of dementia. These tests are not widely used or routinely ordered. Their use is limited to those suspected of dementia, and testing is typically performed after other causes of a person's symptoms have been ruled out.

Visits to a neurologist may be two times or three-four times per year according to the patient's condition. For the calculation of costs, a model example was used. It includes two visits to a neurologist per year, blood tests twice per year, sampling of CSF once per year, H-tau test once per year, and the cost of medication. ${ }^{6}$

A total of 2,627.52 points were required and an amount of $€ 97$ was spent (point value for 2014 was $€ 0.037$ ). This needs to include the cost of drugs, which is $€ 1,745$ per year. ${ }^{6}$ The average annual cost of outpatient treatment per patient was $€ 1,842$ per year. The situation of the patients examined with DG G30, G30.0, and G30.1 in the University Hospital of Hradec Králové is described in the Table 2.

\section{Inpatient care and its costs}

A total of 8,669 cases with primary diagnosis F01, F03, and G30 (dementia) were hospitalized in psychiatric inpatient facilities. Regarding Alzheimer's disease, the

Table I Average costs per patient in the outpatient care

\begin{tabular}{llll}
\hline Examination & $\begin{array}{l}\text { Type of } \\
\text { Laboratory test }\end{array}$ & Points & Cost (€) \\
\hline First visit to the & Comprehensive & 651.00 & 24 \\
neurologist & Special & 139.00 & 5 \\
Second and other visits & Targeted & 330.00 & 12 \\
to the neurologist & Special & 139.00 & 5 \\
Blood sampling twice & Followed person & 10.00 & 0.4 \\
per year & Ceruloplasmin & 73.44 & 3 \\
Sampling of cerebrospinal & Copper & 86.00 & 3 \\
fluid once per year & H-tau & 283.00 & 10 \\
Total & & 629.00 & 23 \\
\hline
\end{tabular}

Notes: Data from Department of Neurology, University Hospital Hradec Králové. 2014. Available from: http://www.fnhk.cz/neuro, ${ }^{6}$ Korabecny M. Pharmacotherapy of Alzheimer's disease: current state and future perspectives. Frontiers in Drug Des Discov. 2014;6:702-738 ${ }^{19}$ and own calculations (CZK/EUR, exchange rate is based on data from the European Central Bank, accessed April 14, 2015) ${ }^{20}$ Points represent the assessment of particular medical examination or treatment according to the Act No $324 / 2014$ Coll. $^{8}$
Table 2 Total number of patients examined with ICD Alzheimer's Disease codes (DG G30, G30.0, and G30.I) in the University Hospital of Hradec Králové

\begin{tabular}{llllll}
\hline Year/diagnosis & $\mathbf{G 3 0}$ & $\mathbf{G 3 0 0}$ & $\mathbf{G 3 0 I}$ & $\mathbf{G 3 0 8}$ & $\mathbf{G 3 0 9}$ \\
\hline 2010 & 52 & 2 & 2 & 10 & 38 \\
$201 \mathrm{I}$ & 40 & 2 & 9 & 7 & 22 \\
2012 & 33 & 2 & 14 & 9 & 8 \\
2013 & 34 & 3 & 16 & 7 & 7 \\
$2014(\mathrm{I}-10)^{*}$ & 64 & 12 & 32 & $\mathrm{II}$ & 9 \\
Total & 223 & 21 & 73 & 44 & 84 \\
\hline
\end{tabular}

Notes: Data from Department of Neurology, University Hospital Hradec Králové. 2014. Available from: http://www.fnhk.cz/neuro, ${ }^{6}$ and own calculations. *Data was only available for the first 10 months of 2014 .

Abbreviations: DG, diagnose; ICD, International Classification of Diseases.

most commonly hospitalized cases were with the diagnosis G30.1, Alzheimer's disease with late onset (more than 38\%, 1,468 cases). Between 2008 and 2012, the total number of hospitalizations of patients with dementia increased by almost a fifth (from 7,363 to 8,669). The largest increase was for Alzheimer's disease (by almost 44\%, ie, 1,170 hospitalizations). ${ }^{2}$

The number of hospitalizations for Alzheimer's disease with late onset (DG G30.1) increased by 37\% (ie, 393), and it increased by $29 \%$ (from 765 to 990 hospitalizations) for Alzheimer's disease unspecified (DG G30.9). The number of hospitalizations of patients with Alzheimer's disease with early onset (DG G30.0) increased only minimally in the reporting period. ${ }^{2}$ The longest treatment time on average in the reporting period was reported for Alzheimer's disease (90 days), including Alzheimer's disease with late onset with more than 112 days and Alzheimer's disease with early onset with 97 days. $^{2}$

In 2012, a total of 8,669 patients with dementia, ie, with basic diagnosis of F01, F03 and G30, were hospitalized in inpatient care facilities. The proportion of hospitalizations of patients with diagnosis of F01, vascular dementia, was $36 \%$ (3,129 hospitalizations) and diagnosis of G30, Alzheimer's disease, was 44\% (3,815 hospitalizations); one-fifth of the hospitalizations was linked with the diagnosis of F03, unspecified dementia (1,725 hospitalizations). ${ }^{2,9}$ Table 3 describes costs for inpatient care from 2010 to 2014 in the Czech Republic.

Table 4 illustrates the overall number of patients with a particular diagnosis and also the cost required for treatment. It is obvious that if the disease is diagnosed earlier (G30.0), the cost is nearly two times lower than that in the later stage (G30.1). This fact supports the initial assumption of the author's team. The implication is evident. First, the public health institutions can use this information for the purpose of prevention support and also for motivating endangered groups of people to visit doctors regularly. Moreover, the 
Table 3 Overview of costs for inpatient care from 2010 to 2014

\begin{tabular}{|c|c|c|c|c|c|}
\hline Time period & Diagnosis* & $\begin{array}{l}\text { Length of } \\
\text { hospitalization (days) }\end{array}$ & $\begin{array}{l}\text { Average length of } \\
\text { hospitalization (days) }\end{array}$ & $\begin{array}{l}\text { Average cost per } \\
\text { hospitalization }(€)\end{array}$ & $\begin{array}{l}\text { Cost for } \\
\text { hospitalization }(€)\end{array}$ \\
\hline \multirow[t]{4}{*}{2010} & G30I & 7 & 6.5 & 316 & 372 \\
\hline & G30I & 1 & & & 74 \\
\hline & G30I & 12 & & & 526 \\
\hline & G309 & 6 & & & 292 \\
\hline \multirow[t]{5}{*}{2011} & G300 & 9 & 7.8 & 356 & 402 \\
\hline & G30I & 7 & & & 342 \\
\hline & G30I & 14 & & & 624 \\
\hline & G308 & 9 & & & 425 \\
\hline & G309 & 0 & & & 0 \\
\hline \multirow[t]{3}{*}{2012} & G300 & 4 & 12 & 496 & 211 \\
\hline & G30I & 28 & & & 096 \\
\hline & G308 & 4 & & & $|8|$ \\
\hline \multirow[t]{5}{*}{2013} & G300 & 7 & 10 & 461 & 327 \\
\hline & G308 & 14 & & & 603 \\
\hline & G309 & 16 & & & 708 \\
\hline & G309 & 9 & & & 434 \\
\hline & G309 & 4 & & & 228 \\
\hline \multirow[t]{3}{*}{$2014(1-10)^{\wedge}$} & G30I & 26 & 15 & 680 & 1,116 \\
\hline & G308 & 5 & & & 267 \\
\hline & G309 & 15 & & & 663 \\
\hline
\end{tabular}

Notes: Data from Department of Neurology, University Hospital Hradec Králové. 20I4. Available from: http://www.fnhk.cz/neuro, ${ }^{6}$ and own calculations (CZK/EUR, exchange rate is based on data from the European Central Bank, accessed April I4, 20I5). ${ }^{20} *$ ICD Alzheimer's Disease codes. ^Data was only available for the first I0 months of 2014.

government might be interested in these outcomes and allocate financial resources more appropriately.

Health care is provided to people with dementia in the form of outpatient and inpatient care. In 2012, approximately 37,000 patients were treated in psychiatric outpatient facilities; other care (not covered by statistics) was provided in neurological and geriatric clinics. In the case

Table 4 Overview of the costs per patient from 2010 to 2014

\begin{tabular}{lll}
\hline Diagnosis* & $\begin{array}{l}\text { Number of } \\
\text { patients }\end{array}$ & $\begin{array}{l}\text { Average cost per } \\
\text { patient }(\boldsymbol{\epsilon})\end{array}$ \\
\hline $\mathbf{G 3 0}$ & & \\
2010 & 2 & 4,527 \\
2011 & 8 & 3,303 \\
2012 & 9 & 3,392 \\
2013 & 3 & 2,088 \\
2014 & 6 & 2,817 \\
$\mathbf{G 3 0 . 0}$ & & \\
2010 & 165 & 3,329 \\
2011 & 174 & 4,561 \\
2012 & 160 & 4,837 \\
2013 & 141 & 4,380 \\
2014 & 151 & 5,026 \\
$\mathbf{G} 30.1$ & & \\
2010 & 396 & 6,675 \\
2011 & 379 & 9,452 \\
2012 & 414 & 8,971 \\
2013 & 394 & 8,625 \\
2014 & 386 & 9,105 \\
\hline
\end{tabular}

Notes: Data from General Health Insurance Company (Všeobecná zdravotní pojišt'ovna). Annual Report 2013. General Health Insurance Company; 2015. [online] Available from: http://www.vzp.cz/uploads/document/vzp-rocenka-2013.pdf. Czech, ${ }^{5}$ and own calculations (CZK/EUR, exchange rate is based on data from the European Central Bank, accessed April 14, 20I5). ${ }^{20}$ *ICD Alzheimer's Disease codes. of inpatient care, over 8,500 hospitalizations of people with dementia were recorded, and the average length of treatment was 78 days. People with dementia were most frequently hospitalized in psychiatric institutions and hospitals. The number of hospitalizations of people with dementia slightly increased in the last 5 monitored years by a few percent, in line with the declining average length of treatment. In case of hospitalized patients, the number of hospitalizations is monitored as a patient may be hospitalized more than once during the reporting period. Therefore, the number of hospitalized people and the number of hospitalizations vary. The comparison of the provided care in terms of sex is relevant as well. Two-thirds (65\%) of hospitalized patients in outpatient care are women; in inpatient care it is $64 \%$. When standardizing the data with the number of people of the given sex in these age groups, the differences among the sexes are not significant. ${ }^{9}$

Standardized data indicate that approximately a quarter (26\%) of people with dementia use outpatient health care and less than $6 \%$ use inpatient care. The investigation showed that the underpinning of patients with Alzheimer's disease at early onset is advantageous from an economic perspective because the cost of outpatient care is much lower compared with inpatient care. Furthermore, after discharge from hospital, the patient is usually transported to a facility for follow-up care, eg, departments for long-term patients. Family care is usually impossible due to high demands on provided services. ${ }^{10}$ In the regions of the Czech Republic, there are fundamental 
differences that deserve a more detailed investigation. The amount of care needed for patients with dementia is lowest in the Liberec Region and South Bohemian Region, and highest in the Moravian-Silesian Region. The amount of people with dementia who are provided with health services differ significantly among regions. In the case of inpatient care the amounts are twice as high, whereas in the case of outpatient care these are sometimes three times greater. In the regions, it is not possible to trace important context and relationships among various types of services. Therefore, it cannot be stated that one form of service is offset by another. ${ }^{11}$

The conducted research and the performed analysis are linked with a particular extent of inaccuracy, because of the lack of the public and nonpublic data. Therefore, expert estimates are used. This fact should be taken into consideration, which might be a challenge for further research.

\section{Conclusion}

The international comparisons of the volume of care provided should be approached with great caution. These comparisons are based solely on the results from various expert estimations and are not usually supported by hard data. Yet, they still illustrate an overall view of our ability to take care of people with dementia. According to the experts, the care in the Czech Republic significantly lags behind the rest of developed Europe. ${ }^{12-14}$ While services are provided to $26 \%$ of people with dementia in Germany and 50\% in France, the experts estimate that services are provided to only $10 \%$ of the population in the Czech Republic. If we were to offer a similar volume of services in the Czech Republic, to the same extent as the average in Europe, we would have to triple the existing capacities. ${ }^{9,15}$ Hort et $\mathrm{al}^{7}$ and Wimo et al ${ }^{1}$ have provided a lot of useful recommendations, linked especially with good practices. They have emphasized the assessment, interpretation, and treatment of patients' symptoms, disabilities, and specific needs.

Even more complicated comparison with other European Union states is within the social care of patients with Alzheimer's disease. ${ }^{16-18}$ Unlike health care in social services, there is no regularly published information that would cover the issue of dementia. Publicly available information in the registers of social service providers does not help in identifying providers aimed at people with dementia. Moreover, the volume of care provided is certainly not sufficient. In the search, it is possible to choose the type of social service provided according to the target group of clients. The target group is closest to the category of people with chronic intellectual illness and, to some extent, to the category of older people. The latter mentioned categories are covered mostly in terms of social services, mainly represented by daycare centers and special homes.

\section{Acknowledgments}

This study was supported by the project Excellence 2015 (Faculty of Informatics and Management, University of Hradec Králové), project PRVOUK: P37/08, and UHK long-term development plan. Moreover, the authors would like to thank the Department of Neurology, University Hospital Hradec Králové, Czech Republic, for the data provision.

\section{Disclosure}

The authors report no conflicts of interest in this work.

\section{References}

1. Wimo A, Gustavsson A, McDaid D, et al. The economic impact of dementia in Europe in 2008: cost estimates from the Eurocode project. Int J Geriatr Psychiatry. 2010;26:825-832.

2. Institute of Health Information and Statistics of the Czech Republic (Ústav zdravotnických a statistických informací). International Statistical Classification of Diseases and Related Health Problems. Institute of Health Information and Statistics of the Czech Republic; 2014. Available from: http://www.uzis.cz/cz/mkn/index.html

3. Research Institute for Labor and Social Affairs (RILSA). Official Websites. Czech Republic; Prague; 2015. [Online] Available from: http:// www.vupsv.cz/?p=index\&site=en. Accessed: August 9, 2015.

4. Drummond MF, O'Brien BJ. Methods for the Economic Evaluation of Health Care Programs. 2nd ed. New York: Oxford Medical Publication; 1997.

5. General Health Insurance Company (Všeobecná zdravotní pojištovna). Annual Report 2013. General Health Insurance Company; 2015. [online] Available from: http://www.vzp.cz/uploads/document/vzp-rocenka2013.pdf. Czech.

6. Department of Neurology, University Hospital Hradec Králové. 2014 Available from: http://www.fnhk.cz/neuro. Accessed January 2, 2015.

7. Hort J, O'Brien J, Gainotti G, et al. EFNS guidelines for the diagnosis and management of Alzheimer's disease. Eur J Neurol. 2010; $17: 1236-1248$.

8. Ministry of Health of the Czech Republic. Act No. 324/2014 Coll. Ministry of Health of the Czech Republic: Prague; 2015. Available from: http://www.mzcr.cz/Legislativa/dokumenty/vyhlaska-c324/2014 sb-o-stanoveni-hodnot-boduvyse-uhrad-hrazenych-sluzeb-a_9871_11. html. Accessed: April 4, 2015.

9. Czech statistical department. Results of Czech Health Accounts 2000-2012. Prague; 2014. Available from: https://www.czso.cz/csu/ czso/vysledky-zdravotnickych-uctu-cr-2000-az-2012-efsq7vjwwi. Czech. Accessed: January 28, 2015.

10. Zdraví a zdravotnictví. Homecare (Domácí péče). Czech Republic; Prague; 2000. [Online] Available from: http://www.zdrav.cz/modules. php?op $=$ modload $\&$ name $=$ News $\&$ file $=$ article $\&$ sid $=1666 \&$ mode $=$ threa d\&order $=0$. Accessed: February 14, 2015.

11. Marešová P, Mohelská H, Kuča K. Cooperation Policy of Rare Diseases in the European Union. Procedia Soc Behav Sci. 2015;171:1302-1308.

12. Dlouhý M, Bartak M. Mental health financing in six eastern European countries. E M Ekon Manag. 2013;16(4):4-13.

13. Marešová $\mathrm{P}$, Tomaskova H, Kuča K. The Use of Simulation Modelling in the Analysis of the Economic Aspects of Diseases in Old Age: EBES Conference Eurasia Business and Economics. In press 2014. 
14. Marešová P, Mohelská H, Kuča K. Economics Aspects of Ageing Population. WCBEM: 3rd World Conference on Business, Economics and Management. Rome: World Education Center; 2014:6.

15. Mohelská H, Marešová $\mathrm{P}, \mathrm{Kuča} \mathrm{K}$. Economic and Managerial Aspects of Alzheimer's Disease in the Czech Republic. 3rd World Conference on Business, Economics and Management (BEM-2014). Procedia Economics and Finance. 2015;23:521-524.

16. Matl O, Holmerova I, Matlova M. Report on Dementia State in Czech Republic. Czech Alzheimer Society: Prague; 2014. Available from: http://www.alzheimer.cz/alzheimerova-choroba-v-cr/zverejnenazprava-o-stavu-demence-2014/. Accessed 2014.
17. Šltés $\mathrm{V}$, Gavurová $\mathrm{B}$. The functionality comparison of the health care systems by the analytical hierarchy process method. E M Ekon Manag. 2014;17(3):100-117.

18. Šoltés M, Gavurová B. Identification of the functionality level of day surgery in Slovakia. J Econ. 2014;62(10):1031-1051.

19. Korabecny M. Pharmacotherapy of Alzheimer's disease: current state and future perspectives. Frontiers in Drug Des Discov. 2014;6: 702-738.

20. European Central Bank. Euro foreign exchange reference rates. [Online] Available from: https://www.ecb.europa.eu/stats/exchange/eurofxref/ html/index.en.html. Accessed: April 14, 2015.

\section{Publish your work in this journal}

Neuropsychiatric Disease and Treatment is an international, peerreviewed journal of clinical therapeutics and pharmacology focusing on concise rapid reporting of clinical or pre-clinical studies on a range of neuropsychiatric and neurological disorders. This journal is indexed on PubMed Central, the 'PsycINFO' database and CAS, and is the official journal of The International Neuropsychiatric Association (INA). The manuscript management system is completely online and includes a very quick and fair peer-review system, which is all easy to use. Visit http://www.dovepress.com/testimonials.php to read real quotes from published authors.

Submit your manuscript here: http://www.dovepress.com/neuropsychiatric-disease-and-treatment-journal 